\title{
Space Observations and Global Climatic Data Reanalysis in AERMOD Modeling Package to Enhance the Industrial Air Pollution and Health Risk Assessment
}

\author{
Marina Faminskaya \\ Russian Social State University, Moscow, Russia \\ Email: Faminskaya@mail.ru
}

How to cite this paper: Faminskaya, M (2020). Space Observations and Global Climatic Data Reanalysis in AERMOD Modeling Package to Enhance the Industrial Air Pollution and Health Risk Assessment. Journal of Geoscience and Environment Protection, $8,65-83$.

https://doi.org/10.4236/gep.2020.87004

Received: May 11, 2020

Accepted: July 17, 2020

Published: July 20, 2020

Copyright $\odot 2020$ by author(s) and Scientific Research Publishing Inc. This work is licensed under the Creative Commons Attribution International License (CC BY 4.0).

http://creativecommons.org/licenses/by/4.0/ Open Access

\begin{abstract}
We try to enhance the AERMOD industrial pollution dispersion model with remote sensing observations and climatic models based on them. In this paper, we focus on surface parameters (albedo, roughness, Bowen ratio) and land use classification on which they depend. We model maximum hourly concentrations and the resulting acute health risk and assess the effect on them produced by using remote sensing data for local areas around industrial plants instead of global standard AERMOD parameters. We consider five real multi-source plants for the effect of classification and two of them for the effect of surface parameters. The effect on the critical pollutant is measured in three ways: a) as difference between the yearly maxima of hourly concentrations of a critical pollutant ("absolute"); b) the same limited to daytime workhours and 95\% quantile instead of absolute maximum ("regulatory"); c) as maximum hourly difference over a year ("instant"). The measure of effect is divided either by the reference concentration of the pollutant, which yields the impact on health risk, or by the concentration obtained with AERMOD standards, which yields relative measure of impact. For a), the impact of roughness dominates, that of albedo is small and that of the Bowen ratio is almost zero. For b), the impact of roughness is less prominent, and that of albedo and Bowen ratio is noticeable. For c), the impact is considerable for all three parameters. The effect of land use classification is considerable in all three cases a) - c). We provide the figures for different measures of remote sensing data effect and discuss the perspective of using remote sensing data in regulatory context.
\end{abstract}

\section{Keywords}

Pollutant Dispersion Model, AERMOD, Albedo, Bowen Parameter, 
Roughness, Landsat, ALOS, GLASS, ERA5

\section{Introduction}

AERMOD is one of the most widely used pollutant dispersion modeling tools for assessing the health risk from industrial air pollution. It contains a micrometeorological model based on the description of surface by albedo, Bowen parameter, and roughness using global standards for land cover categories. Since the introduction of AERMOD, many potentially useful free data have become available through space observations of surface and atmosphere and through reanalysis databases oriented mainly to climatic research.

In this paper, we study the potential application of these new data sources to AERMOD pollution modeling. Our research is self-constrained by not encroaching on the micrometeorological model built into AERMOD as its component processor AERMET: we introduce new data only through channels provided by AERMOD. This paper focuses on two parameters directly reconstructed from space observations (albedo and roughness) and one (Bowen parameter), which requires the in-depth modeling of heat flux balance.

The usual AERMOD workflow takes an existing land use category map (NLCD for US) and applies to each category its standard (seasonally dependent) values of albedo, roughness and Bowen parameter specified by AERSURFACE module. These standards do not depend on specific location of the plant modelled and, in this sense, are global and easy to use. Bringing in the local specific remote sensing data for land use and surface parameters adds to the already considerable complexity of pollution dispersion modeling. However, we think it is justified: it is expected to improve the accuracy of surface parameters input into the model and hence of modelled concentrations and health risks. In our experience, local surface parameters reconstructed from remote sensing data can be radically different from AERMOD global standards both in absolute value and in seasonal dynamics. One example is given in this paper for Bowen parameter; there are many more.

The availability of remote sensing data relevant to AERMOD modeling has been growing. Some of this data is directly applicable to AERMOD (e.g., albedo); some, so far, need a considerable processing effort of the modeler (e.g., roughness and Bowen parameter). Anyway, the replacement of AERMOD global standards by locally specific parameters seems to us inevitable and this paper is an effort in this direction.

We show how several types of space-based data can be used in AERMOD, and assess to what extent their use changes the modeled pollutant concentrations important for human health. We do this for a selection of five different industrial plants, with a special focus on two: a coke chemical plant and a cleaning station (Balter \& Faminskaya 2017). 
The main result of this paper is the quantitative measure of the impact on model concentrations exerted by the use of locally specific remote sensing data instead of AERMOD global standards. The impact is different depending on the surface parameter to which remote sensing data are applied and on the criteria used to measure the impact. Three different criteria are discussed, each applicable in an appropriate regulatory or non-regulatory context.

\section{Methodology and Data}

We begin with a short review of remote sensing data processing for parameters relevant to AERMOD and of existing databases of such parameters. Most of these efforts are oriented to climatic models rather than to pollution dispersion models. Nevertheless, several experiments using this data with AERMOD give a general picture of the extent to which various data influence the modelled pollutant concentrations. This paper supports this picture and refines it. We studied the available datasets, selected those that yield reasonable values of AERMOD input parameters, and interfaced them with AERMOD.

Then, we describe the data and methodology used in this paper. We modelled five Russian industrial plants for which we had the emission data and local meteorological data. Remote sensing/reanalysis data used to enhance AERMOD modelling for each plant were from Landsat, GLASS and ERA5 databases. We describe three criteria for measuring the impact of using this data, in contrast to usual AERMOD standards: "absolute", "regulatory" and "instant".

\subsection{Review of Space Data Usable in Pollutant Dispersion Models}

The use of space data is built into AERMOD from its very beginning since its surface parameter processor AERSURFACE relies on ready-made Landsat-based classification of US territory into 21 NLCD-92 categories (AERSURFACE User's Guide, 2008). Each category is assigned its specific season-dependent default surface parameters (called below "AERMOD standards"). However, such classifications are not available everywhere outside US, at least, not as detailed as NLCD-92, and, anyway, the global applicability of AERMOD standard parameters is questionable. The Landsat/AERSURFACE approach can be extended or replaced with other types of data. One can a) produce a NLCD-92-compatible classification of land use and then apply the AERSURFACE defaults; or b) estimate directly the surface parameters required by AERMOD (albedo and roughness); or c) use the parameters of atmosphere provided by existing global climatic models for an estimate of Bowen coefficient or directly integrate these parameters into AERMOD workflow. Below, we give a short review of these three lines of remote sensing data processing; however, they are seldom used with AERMOD.

In the line a), the simplest approach is to use an existing land use classification (Bo et al., 2015) translates the US EPA approach to Chinese situation using an existing land use GIS, which implied reassignment of GIS categories to 
NLCD-92. The same approach was used in Thailand (Pongprueksa \& Chatchupong, 2016). Alternatively, one can use the global land use classification GLC30 with a 30-meter resolution or GLC10 with a 10-meter resolution, but both use a coarser category system than NLCD-92, especially for built-up areas. Another global land use classification based on MODIS data is MCD12Q1 (Garcia-Mora et al., 2012); it has a lower resolution (500 m) but for AERMOD, this may be sufficient. Using GLC30, GLC10 and MCD12Q1 with AERMOD was considered in (Balter et al., 2018). Rather than using a global classification, one can produce a classification of Landsat data based on locally chosen training sites, as in this paper.

In the line b), broadband albedo can be reliably estimated from many spaceborne optical sensors. It is widely used in climatic research-see a comprehensive review in (He et al., 2018). Landsat and MODIS are the most used sensors if the tens-to-hundreds meter resolution is required. (Pape \& Vohland 2010) compares these data and provides the broadband albedo formulae for both sources in Lambertian approximation. (Baldinelli et al., 2017), in a study of urban heat island, show that the broadband albedo formulae need correction in this context.

In the line b), roughness estimation uses different approaches for smaller $(<\sim 1$ $\mathrm{m})$ and larger $(>\sim 1 \mathrm{~m})$ roughness values. The first type is characteristic of grasslands, crops, et al., and the second type, of forests and buildings. Smaller roughness is either directly observed from radar backscatter or estimated from models based on optical observation of vegetation parameters such as NDVI (Gupta et al., 2002) or LAI (Gowda et al., 2008). In (Cho et al., 2012), vegetation roughness is related to albedo. Larger roughness can be observed by radar or by optical stereoscopy as in ALOS (Tadono et al., 2016); for a forest, it can be estimated from LAI-based models. In this paper, we use NDVI and ALOS for small and large roughness, respectively. In urban context, a perspective direction is combining the remote sensing digital elevation models (DEMs) with GIS data on buildings (e.g., Open Street Map OSM). Recently, a specialized processor UMEP (Lindberg et al., 2018) was developed for this purpose.

Estimating the Bowen parameter lies in the line c) since there is no direct method to obtain it from space observations. It is based on climatic/mesoscale meteorological models, which assimilate the remote sensing data. We use two methods for Bowen parameter: a) the ratio of gradients of potential temperature and specific humidity in the model-based vertical profiles of the atmosphere; $b$ ) the ratio of sensible to latent heat flux at the surface calculated from the balance of incoming and outgoing shortwave and longwave radiation. Both methods are well known and compared, e.g., in (Malek, 1993). However, there is a lack of publications on applying them with remote sensing data to estimate the Bowen parameter.

With the introduction in AERMOD of dependence on the above-mentioned surface parameters, several studies estimated the sensitivity of model concentrations to them. (Grosch \& Lee, 1999) concludes, for a surface source, that "only 
the surface roughness length affects the design concentrations significantly; albedo and Bowen ratio have little or no effect on the annual design concentrations". There was almost no effect of albedo or Bowen parameter on maximal 1-hr or 3-hr concentrations because they are formed in stable conditions, mostly at night, when these parameters do not enter the AERMET algorithm. For elevated sources, the impact of albedo and Bowen parameter was considerable because, for a high stack, the maximal concentrations occur near midday. Currently, the general consensus is that "AERMOD is highly sensitive to changes in surface roughness length and rather indifferent to albedo and Bowen ratio variations" (Karvounis et al., 2007). Usually, these studies deal with an isolated source, while in this paper we deal with real plants, which include a mix of surface and elevated sources.

There is a growing interest in using the existing mesoscale meteorological models in air quality modeling: MM5 (Isakov et al., 2007), WRF (Kumar et al., 2017; Kesarkar et al., 2007) and others. Because of the coarse spatial resolution of such models, they are mostly used in conjunction with air quality models of a coarser resolution than AERMOD. When used with AERMOD, these models are usually considered as a replacement of the local meteorological data or of the model embedded in AERMET (Kesarkar et al., 2007). In contrast, we consider such models as an addition to local meteorology used by AERMET model. Midway between climatic/meteorological models and remote sensing observations are the reanalysis databases, e.g., GLASS (Global Land Surface Satellite), which we use in this paper. They may still have a coarser resolution than that required by AERMOD. However, in the industrial context with sources concentrated in space, the problem is alleviated since resolution of health impact is determined only by the model grid, which is usually much denser than reanalysis or climatic model data.

\subsection{Data Used in This Paper}

We have chosen five Russian plants for the variety of their industries and locations (Table 1). For all plants, we included the full set of their pollution sources, as reported in their regulatory documents. To simplify the interpretation of results, all sources were assumed to work uninterruptedly, with constant emission rates, in contrast to regulatory dispersion modeling (Balter \& Faminskaya, 2017). Modeling was performed for years 2013-2018. To study the impact of space-based land use classification on pollutant concentrations, we compared two regimes: Landsat-based land use classification with local training sites and existing global land use maps (mostly GLC10), which we translated into NLCD-92 category system. For the impact of three other parameters, we have concentrated on the first two plants and compared two model regimes based on Landsat land use classification: the one with AERMOD standards (STD), and the "experimental" one, which substituted one of three surface parameters with values derived from remote sensing data and/or from reanalysis databases. The two remote data 
Table 1. Plants and maximal hourly $\left(\mathrm{C}_{\max }\right)$ and yearly average $\left(\mathrm{C}_{\text {avg }}\right)$ concentrations $\left(\mathrm{mg} / \mathrm{m}^{3}\right)$ of critical pollutants calculated for critical points outside exclusion zones. In relation to acute and chronic reference concentrations $\mathrm{RFC}_{\mathrm{ac}}, \mathrm{RFC}_{\mathrm{ch}}$. Modeled with land use classification based on standard data (GLC30, GLC10, MOD12Q1).

\begin{tabular}{cccccc}
\hline Plant \# & $\mathbf{1}$ & $\mathbf{2}$ & $\mathbf{3}$ & $\mathbf{4}$ & $\mathbf{5}$ \\
\hline Industry type & Coke chemistry & Cleaning station & Metallurgy & Petroleum depot & Pulp and paper \\
Coordinates & $56 \mathrm{~N}, 38 \mathrm{E}$ & $44 \mathrm{~N}, 44 \mathrm{E}$ & $55 \mathrm{~N}, 59 \mathrm{E}$ & $45 \mathrm{~N}, 38 \mathrm{E}$ & $59 \mathrm{~N}, 38 \mathrm{E}$ \\
Main pollutant & Coke dust & $\mathrm{NO} 2$ & Ferromanganese dust & Hydrocarbons C1-C5 & Wood dust \\
$\mathrm{C}_{\text {max }} / \mathrm{RFC}_{\mathrm{ac}}$ & $1.2=0.35 / 0.3$ & $2=0.4 / 0.2$ & $4.7=1.4 / 0.3$ & $3.2=29 / 9$ & $1.3=0.63 / 0.5$ \\
$\mathrm{C}_{\text {avg }} / \mathrm{RFC}_{\mathrm{ch}}$ & $0.4=0.03 / 0.075$ & $0.75=0.03 / 0.04$ & $0.27=0.02 / 0.075$ & $0.2=0.04 / 0.2$ & $0.07=0.005 / 0.075$ \\
\hline
\end{tabular}

sources most used in this work were Landsat and GLASS (Zhao et al., 2013) although not all GLASS datasets cover the entire time span 2013-2018.

We studied the available datasets, selected those that yield reasonable values of AERMOD input parameters, and interfaced them with AERMOD. Then, we studied the impact on maximal hourly model concentrations of replacing AERMOD standards with space-based surface parameter estimates.

\subsection{Measures of Remote Sensing Data Impact on Pollutant Dispersion}

By "impact" we mean the difference in modelled pollutant concentrations between "what we are proposing" (using remote sensing data) and "what was before" (using AERSURFACE standards). We estimated this impact in three ways. First, by comparing the absolute yearly maxima of concentrations in each region around the plant. This is a common regulatory indicator but it is less influenced by space/reanalysis data because maxima are usually formed in stable atmosphere, especially in nighttime, when albedo and Bowen parameter do not enter the AERMOD algorithm. We call this measure DiffLast or "absolute" Second, we consider the regulatory situations when the indicator is less dominated by stable conditions: emissions limited to daytime workhours (8:00-17:00) and 95\% quantile, rather than the absolute maximum of concentrations, as the regulatory criterion. We call this measure "regulatory" or Day $95 \%$. Third, the maximal hourly difference of concentrations in each region over a year is taken as the indicator. We call this measure DiffFirst or "instant". It is sensitive to space/reanalysis data because it uses maximum of difference instead of difference of maxima. Its practical importance is debatable but it is a useful criterion for model comparison and adjustment.

\section{Results}

We begin by studying the impact on modelled concentrations exerted by using the specially processed local Landsat data for land use, in contrast to existing ready-made land use maps available on Internet, which we consider as "standard". For US, the AERMOD "standard" would be the NLCD maps, but for Russia, such maps do not exist, and we have to use other freely available land use 
maps: GLC30, GLC10, and MOD12Q1. For both types of maps compared, the AERSURFACE standard parameters are applied to each land use category, which produces differences in all three surface parameters. We assess the resulting differences in maximum hourly concentrations of a critical pollutant (different for each plant) on the surroundings and on the critical region closest to the plant.

Then, we repeat the procedure separately for each of the three surface parameters using in all cases the Landsat-based land use map and contrasting the application of AERSURFACE standards to this map and the surface parameters derived from space data. For albedo, we used Landsat and GLASS; for roughness, ALOS for buildings and forests and GLASS for other vegetation; for Bowen parameter, Landsat, GLASS and ERA5 data.

\subsection{Impact of Classification}

We compared concentrations obtained by applying AERMOD standards to ready-made global land use classifications GLC10, GLC30, and MOD12Q1 (here, only GLC10 is listed) with concentrations obtained by applying them to supervised classification of multi-year Landsat data (weighted maximum likelihood ML) with locally selected training sites, as described in (Balter et al., 2018). The classification procedure uses unsupervised clustering of the full multi-year set of Landsat data cleaned from clouds, selection of training sites corresponding to relevant NLCD-92 categories within clusters, ML classification, and manual adjustment of category weights to exclude obvious misclassifications. Mapping of GLC30, GLC10, and MOD12Q1categories to NLCD-92 categories is described in (Balter et al., 2018).

Model dispersion calculations were performed for five plants, ignoring the relief and the pulsed character of some emissions. Table 2 shows the results obtained with the global land use map GLC10 and the local Landsat classification LC8.

Three criteria for measuring difference are used; since Day95\% radically cuts the maxima of concentrations, its comparison with other criteria should be done using its ratio to GLC10 rather than to $\mathrm{RFC}_{\mathrm{ac}}$. The effect of using space data for classification is considerable. Its relative (divided by GLC10) impact on concentrations is usually $10 \%-100 \%$. For DiffLast and DiffFirst, the absolute impact is comparable to $\mathrm{RFC}_{\text {acute }}$, which is the threshold of admissibility, somewhat larger in the critical region (residential region with maximal concentrations). Thus, refinement of land use classification with space data has a considerable impact on maximal hourly concentrations of pollutants and hence, on acute health risk. This is due to the influence of land use classification on all three surface parameters (albedo, Bowen, roughness) but the main impact factor is roughness as shown below.

\subsection{Impact of Albedo}

First, we compared the seasonal dynamics of albedo obtained from GLASS and 
Table 2. Difference of maximal hourly concentrations (measured as DiffLast, or absolute, Day95\%, or regulatory, and DiffFirst, or instant) obtained with global land use map GLC10 and local land use map constructed from Landsat (LC8). Difference shown for the critical pollutant in relation to RFCacute and to STD.

\begin{tabular}{|c|c|c|c|c|c|c|c|}
\hline \multirow{3}{*}{ Plant } & \multirow{3}{*}{$\begin{array}{l}\mathrm{RFCac} \\
\mathrm{mg} / \mathrm{m}^{3}\end{array}$} & \multicolumn{3}{|c|}{ |GLC10-LC8| |GLC10-LC8| |GLC10-LC8| } & GLC10-LC8| & \multicolumn{2}{|c|}{ GLC10-LC8| |GLC10-LC8| } \\
\hline & & /RFCac & /GLC10 & /RFCac & /GLC10 & /RFCac & /GLC10 \\
\hline & & DiffFirst & DiffFirst & DiffLast & DiffLast & Day95\% & Day95\% \\
\hline \multicolumn{8}{|c|}{ Average of regions outside exclusion zone } \\
\hline 1 & 0.3 & 0.60 & 0.32 & 0.36 & 0.19 & 0.013 & 0.38 \\
\hline 2 & 0.2 & 0.52 & 0.42 & 0.31 & 0.27 & 0.024 & 0.39 \\
\hline 3 & 0.3 & 0.40 & 0.93 & 0.19 & 0.41 & 0.009 & 0.28 \\
\hline 4 & 9 & 2.43 & 0.31 & 1.04 & 0.14 & 0.046 & 0.26 \\
\hline 5 & 0.5 & 1.06 & 0.68 & 1.20 & 0.58 & 0.01 & 0.77 \\
\hline \multicolumn{8}{|c|}{ Critical region } \\
\hline 1 & 0.3 & 1.31 & 0.34 & 0.86 & 0.22 & 0.021 & 0.36 \\
\hline 2 & 0.2 & 2.57 & 0.37 & 1.63 & 0.23 & 0.24 & 0.19 \\
\hline 3 & 0.3 & 0.46 & 0.98 & 0.18 & 0.39 & 0.004 & 0.16 \\
\hline 4 & 9 & 1.34 & 0.17 & 0.63 & 0.08 & 0.001 & 0.02 \\
\hline 5 & 0.5 & 1.34 & 0.58 & 1.40 & 0.56 & 0.0017 & 0.20 \\
\hline
\end{tabular}

Landsat LC8 and that obtained with AERMOD standards. Both GLASS and Landsat show a perceptible increase of albedo in summer, as compared to spring and autumn, which is absent in AERMOD standards. The absolute values of albedo are generally lower than in AERMOD by $\sim 0.05$ for both plants. Winter values are most problematic due to cloudiness; for Plant 1 they more or less correspond to AERMOD values while for Plant 2, the difference is considerable. Figure 1 shows the maps of albedo for Plant 1. Color scale is from violet (minimum) to red (maximum). The same color scale is used throughout this paper. Table 3 shows the summary of dispersion modeling results for Plant 1 - Plant 3 using AERMOD standards denoted STD or albedo from Landsat and GLASS data denoted LC8.

The impact of using space/reanalysis data for albedo is greatest if measured by DiffFirst-15\% - 100\% of $\mathrm{RFC}_{\text {acute }}$. However, this measure of impact is the least relevant in the regulatory sense. DiffLast, except for Plant 1 critical region, is only several percent of $\mathrm{RFC}_{\text {acute }}$, which agrees with the estimates by other authors. Such small refinements of model concentrations can be neglected in regulatory context but refinements can be considerable in some critical regions (as for Plant 1) and/or if Day95\% is more relevant than DiffLast (as for Plant 2). As concentrations cut to $95 \%$ quantile are much lower than absolute maxima, the ratio to STD is more relevant for comparison with DiffLast and DiffFirst than the ratio to $\mathrm{RFC}_{\text {acute }}$. Considering the concentration timeline provides an insight into the reason of small impact of albedo on concentrations.

Figure 2 shows the sensible heat flow $H_{0}$ as an indicator of differences between 


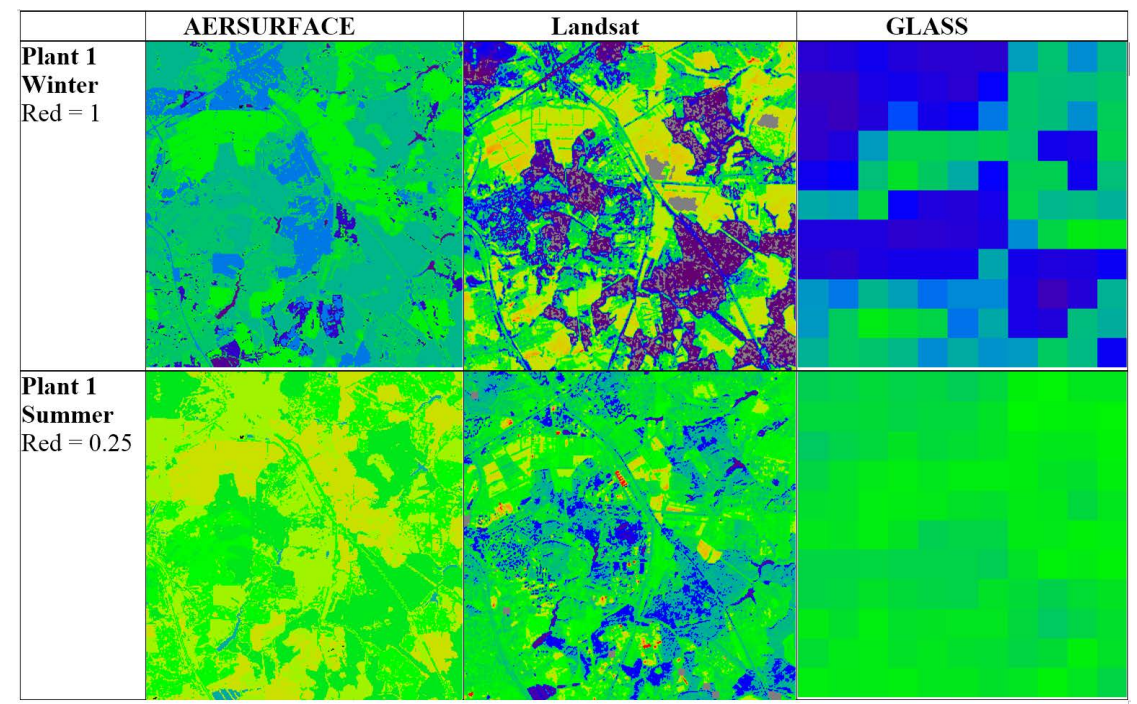

Figure 1. Albedo from AERSURFACE standards, Landsat and GLASS. Plant 1.

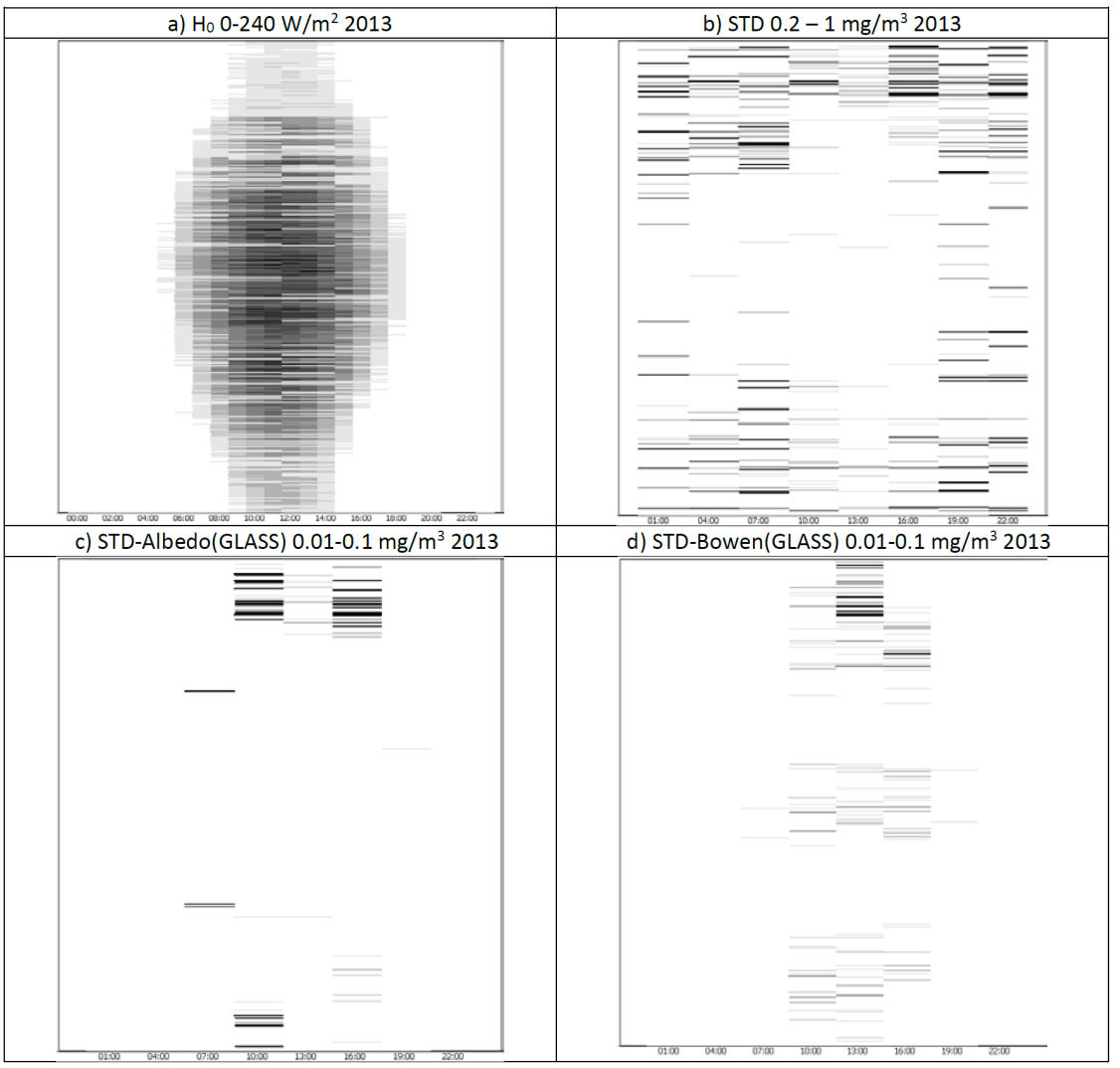

Figure 2. Diagram of hourly (abscissa) vs. daily (top-down: days, 2013) values of: (a) sensible heat flow $H_{0}$, (b) model concentrations for AERMOD standards, (c) concentration differences between (b) and values based on GLASS albedo, (d) concentration differences between (b) and values based on GLASS Bowen parameter (see below).

stable and convective or nightly and daily heat flux. Abscissa is the hour and ordinate is the day of year (starting at top). Convective and daytime situations $\left(H_{0}>0\right)$ are shown in black. 
Table 3. Absolute differences between maximal hourly concentrations of critical pollutant calculated with AERMOD standards (STD) and with Landsat 8 or GLASS data for albedo (LC8).

\begin{tabular}{cccccccc}
\hline Plant & $\begin{array}{c}\text { RFCac } \\
\mathrm{mg} / \mathrm{m}^{3}\end{array}$ & $\begin{array}{c}\mid \text { (STD-LC8) } \mid \\
\text { /RFCac } \\
\text { DiffFirst }\end{array}$ & $\begin{array}{c}\mid \text { /STD } \\
\text { DiffFirst }\end{array}$ & $\begin{array}{c}\text { /RFCac } \\
\text { DiffLast }\end{array}$ & $\begin{array}{c}\text { /STD } \\
\text { DiffLast }\end{array}$ & $\begin{array}{c}\text { /RFCac } \\
\text { Day95\% }\end{array}$ & $\begin{array}{c}\text { /STD } \\
\text { Day95\% }\end{array}$ \\
\hline \multicolumn{7}{c}{ Average of regions outside exclusion zone } \\
1 & 0.3 & 0.15 & 0.11 & 0.035 & 0.02 & 0.0013 & 0.15 \\
2 & 0.2 & 0.56 & 0.55 & 0.009 & 0.008 & 0.027 & 0.17 \\
3 & 0.3 & 0.21 & 0.15 & 0.028 & 0.02 & 0.0084 & 0.0097 \\
& & & & Critical region & & & \\
1 & 0.3 & 0.37 & 0.12 & 0.25 & 0.08 & 0.0003 & 0.0035 \\
2 & 0.2 & 2.6 & 0.53 & 0.02 & 0.045 & 0.26 & 0.16 \\
3 & 0.3 & 1 & 0.35 & 0.029 & 0.07 & 0.031 & 0.011 \\
\hline
\end{tabular}

Peak concentrations (STD diagram) occur mostly for $H_{0}<0$ while the highest impact of GLASS data occurs for $H_{0}>0$ so that concentration peaks are affected by it but rarely.

\subsection{Impact of Roughness}

For roughness, urban and non-urban (vegetated) territories are processed differently. To distinguish them, we use the supervised classification of the territory based on Landsat data. For non-forest vegetation, we use the formula from (Gupta et al., 2002) relating roughness to NDVI in Landsat data. For forests, the formula yields too small values, so that we have adopted the usual assumption of roughness equal to 0.1 of the average forest height estimated from ALOS DEM data in the following manner.

The DEM image is scanned by a moving $7 \times 7$ pixel window called "large", which is covered by $3 \times 3$ pixel sub-windows called "small". For each position of the large window, in each small window within it the operation shown as rows of Table 4 is performed, and then the results of all small windows are aggregated to a single large window value in ways shown as columns of Table 4. For forest height, the small window operation was "minimum" and the aggregation rule "minimum". Subtraction of this smoothed image from the original DEM produces the heights of forest borders as shown for Plant 1 in Figure 3, left. We cut out the values $<7 \mathrm{~m}$, which, presumably, correspond to non-forest borders, and interpolate heights from borders inside the forest plots (Figure 3, right). After translating height to roughness, the seasonal dependence had to be introduced since ALOS DEM is a single multi-year set. We have taken ALOS-based roughness as the maximal summer value and applied to it the seasonal change coefficients adopted from AERMOD standards.

For buildings, we used the same procedure as for forests. The small-window operation applied was the standard deviation (Table 4). Then, we used the regression 
Table 4. Types of two-scale moving window used for forests and buildings. Column: operation performed within the small window; row: operation performed in aggregating small windows to a large window.

\begin{tabular}{|c|c|c|c|}
\hline Small window $\quad$ Large window & Minimum & Mean & $95 \%-5 \%$ quantile \\
\hline 1 pixel value & & & + \\
\hline Standard deviation & & + & \\
\hline $95 \%-5 \%$ quantile & & + & \\
\hline Minimum & + & + & \\
\hline
\end{tabular}

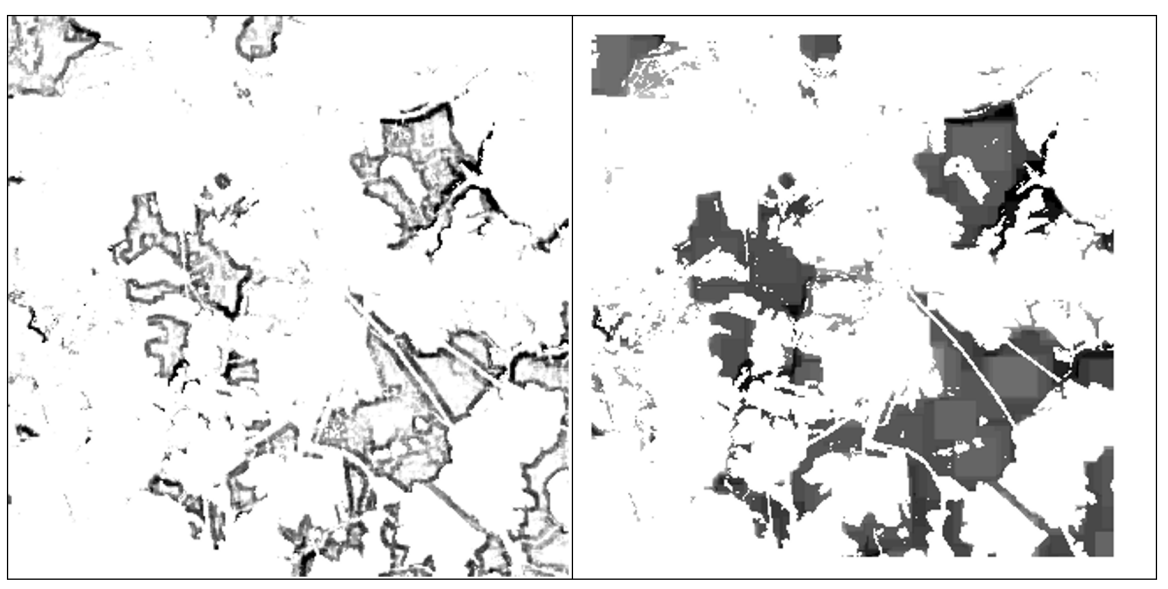

Figure 3. Left: forest height at forest borders constructed by a two-scale moving window from ALOS DEM (Plant 1). Right: forest height interpolated from borders to the interior of closed forest areas. Black: $>30 \mathrm{~m}$, heights $<7 \mathrm{~m}$ not taken into account.

between ALOS-based heights and OSM building heights constructed from combined Plant 1 and Plant 2 data for the areas where OSM is available (Figure 4). The regression has a satisfactory $R^{2}$. Then, we applied the coefficient 0.1 to transform height to roughness.

This approach used some lessons learned from (Simpson et al., 2012) and (Kent et al., 2019). Its two stages are illustrated in Figure 5.

Figure 6 shows the results as maps. In both versions of impact measures, there is a considerable territory where the impact of using Landsat + ALOS data for roughness is significant. This contrasts the situation for albedo where there are no such significant points outside the exclusion zone. The results are summarized in Table 5.

\subsection{Impact of Bowen Parameter}

Extracting the Bowen parameter from space observations involves a full thermal flux model of the area. Therefore, in this section we rely on reanalysis/climatic model data rather than on direct space observations. See (Liang et al., 2019) for review. We consider two different sources of information on Bowen parameter: models of surface heat balance and models of vertical atmospheric profile. The first approach is applied to Plants 1 and 2, and the second one, to Plant 2. The 


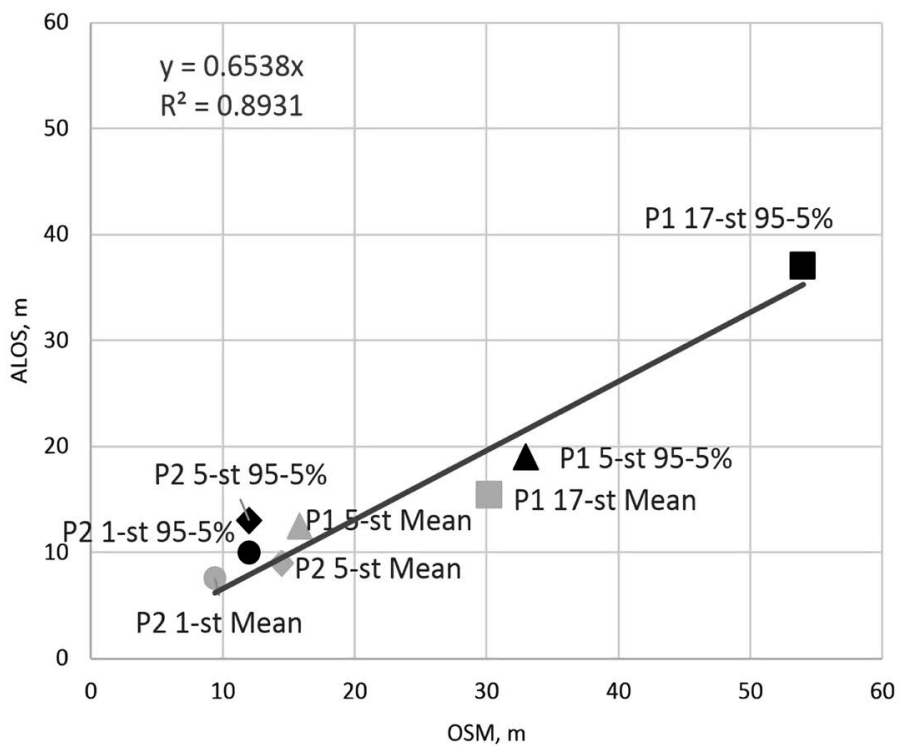

Figure 4. Regression between OSM building heights and the heights reconstructed from moving-window scans of ALOS DEM with two aggregation rules: mean and 95\% - 5\% quantile. For Plant 1 (P1) and Plant 2 (P2), areas with predominant 1-storey, 5-storey and 17-storey buildings.

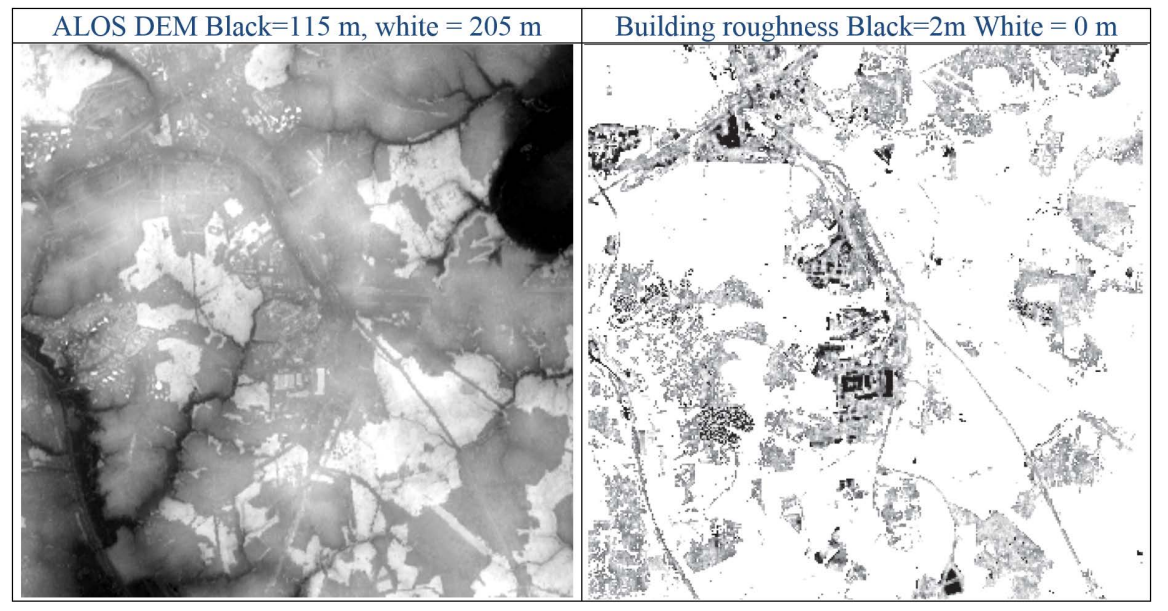

Figure 5. Smoothed ALOS DEM for Plant 1 and building roughness derived from it.

Table 5. Absolute differences between maximal hourly concentrations of critical pollutant calculated with AERSURFACE standards (STD) and with Landsat 8 + ALOS DEM data for roughness (LC8).

\begin{tabular}{|c|c|c|c|c|c|c|c|}
\hline Plant & $\begin{array}{l}\text { RFCac } \\
\mathrm{mg} / \mathrm{m}^{3}\end{array}$ & $\begin{array}{c}\mid(\text { STD-LC8)| } \\
\text { /RFCac } \\
\text { DiffFirst }\end{array}$ & $\begin{array}{c}\mid \text { (STD-LC8) } \\
\text { /STD } \\
\text { DiffFirst }\end{array}$ & $\begin{array}{c}\text { (STD-LC8)| } \\
\text { /RFCac } \\
\text { DiffLast }\end{array}$ & $\begin{array}{c}\mid(\text { STD-LC8)| } \\
\text { /STD } \\
\text { DiffLast }\end{array}$ & $\begin{array}{c}\text { |(STD-LC8)| } \\
\text { /RFCac } \\
\text { Day95\% }\end{array}$ & $\begin{array}{c}\text { |(STD-LC8) } \\
\text { /STD } \\
\text { Day95\% }\end{array}$ \\
\hline \multicolumn{8}{|c|}{ Average of regions outside exclusion zone } \\
\hline 1 & 0.3 & 0.45 & 0.33 & 0.23 & 0.12 & 0.026 & 0.59 \\
\hline 2 & 0.2 & 0.203 & 0.19 & 0.117 & 0.11 & 0.032 & 0.35 \\
\hline \multicolumn{8}{|c|}{ Critical region } \\
\hline 1 & 0.3 & 1.4 & 0.36 & 0.42 & 0.095 & 0.05 & 0.65 \\
\hline 2 & 0.2 & 0.683 & 0.099 & 0.457 & 0.066 & 0.21 & 0.15 \\
\hline
\end{tabular}




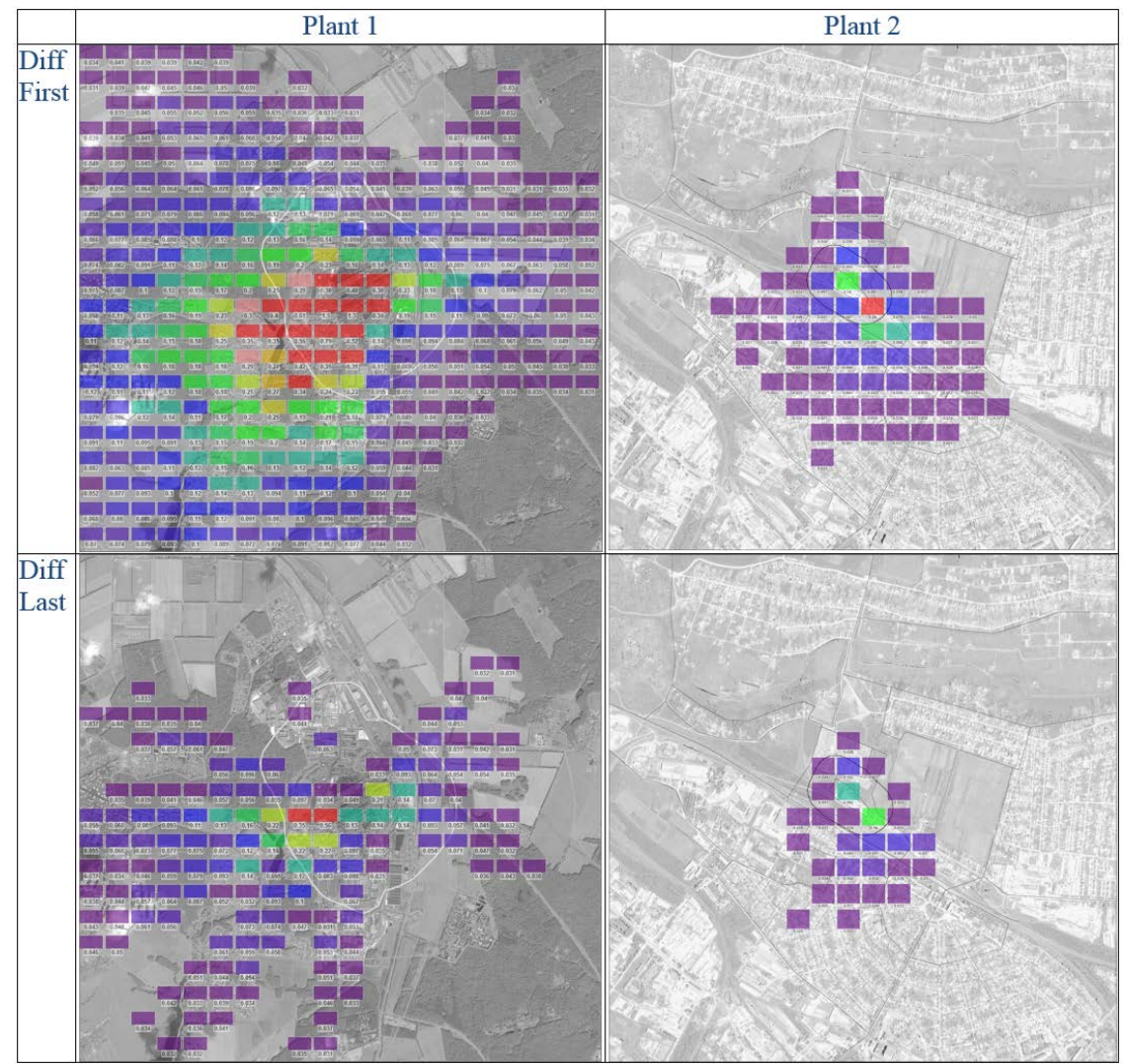

Figure 6. Absolute difference between yearly maxima of critical pollutants for Plant 1 and Plant 2. $\mathrm{Red}=\mathrm{RFC}_{\text {acute }}$, values $<0.1 \mathrm{RFC}_{\text {acute }}$ not shown .

first approach for Plant 1 is more complex and involves data from Landsat and/or GLASS, data from local meteorological stations and several semi-empirical formulae. For Plant 2, we use a simpler version of the first approach based on only GLASS data but with a worse spatial resolution. The second approach uses only data from ERA5 and has the spatial resolution $0.125^{\circ}$ more or less corresponding to the $10 \times 10 \mathrm{~km}$ area characterized by Bowen parameter in AERMOD. In the first approach, we obtain a map of Bowen parameter and, thus, are able to calculate its geometrical rather than arithmetical mean value over the area as recommended by AERSURFACE. In the second approach, we have a single value for the entire area.

The logic of calculations for Plant 1 is the following. Net radiation $R_{n}$ is calculated from downward shortwave radiation, surface albedo, the emissivities of atmosphere and of surface (as a function of NDVI), and the temperatures of air (taken from local meteorological station) and of surface (from thermal channels of remote sensors). We account for atmospheric transmissivity using either the number of sunshine and cloudy hours or precipitable water content. Thermal flux into soil G is calculated from NDVI as in (Bastiaanssen \& Roebeling 1993). Sensible heat flow $H_{0}$ is calculated from the surface-air temperature difference as in SEBAL (Bastiaanssen et al., 1998a, 1998b). Finally, the Bowen parameter Bo is calculated as $H_{0} /\left(R_{n}-G-H_{0}\right)$, where the denominator is the latent heat flow LE. 
With GLASS data for Plant 2, $H_{0}$ is calculated as $H_{0}=R_{n}-G-\mathrm{LE}$, where $R_{n}$ is provided by GLASS reanalysis database at a resolution of $0.05^{\circ}$ and LE at a resolution of $1 \mathrm{~km}$ and 8-day intervals. $\mathrm{G}$ is calculated as for Plant 1 from GLASS data on NDVI. Bowen parameter is calculated as Bo $=H_{0} / \mathrm{LE}$.

With ERA5 data for Plant 2, the potential temperature difference DT is calculated between two lowest levels of ERA5 atmospheric profile (1000 and 975 mbar), and Bo $=\gamma$ DT/De, where $\gamma$ is the psychrometric constant and De is the difference of specific humidity between the two levels.

The resulting maps of Bowen parameter are compared in Figure 7 with maps constructed from AERMOD standards applied to supervised Landsat-based classification. Figure 8 demonstrates that two versions of the seasonal dynamics of Bowen parameter constructed from GLASS and ERA5 are more or less concordant despite the differences in data and algorithms. This speaks in favour of reliability of Bowen parameter obtained from reanalysis data. Both are radically different in value and seasonal trend from AERMOD standards. Thus, we expect that using the remote sensing and reanalysis data would make a considerable difference in Bowen parameter values used by AERMOD.

Table 6 presents the summary of model concentrations. For Plant 1, the impact of Bowen parameter from Landsat data is comparable in magnitude to that of albedo from Landsat data and much weaker than that of roughness. For Plant 2 , the impact is considerably weaker than even that for albedo. The DiffLast impact is close to zero and not shown. The weak impact that Bowen parameter has on maximal concentrations is due to the same reasons as for albedo.

\section{Discussion and Limitations}

Since the official introduction of AERMOD in 2004, many new and potentially useful sources of remote sensing data/reanalysis have appeared. We are interested

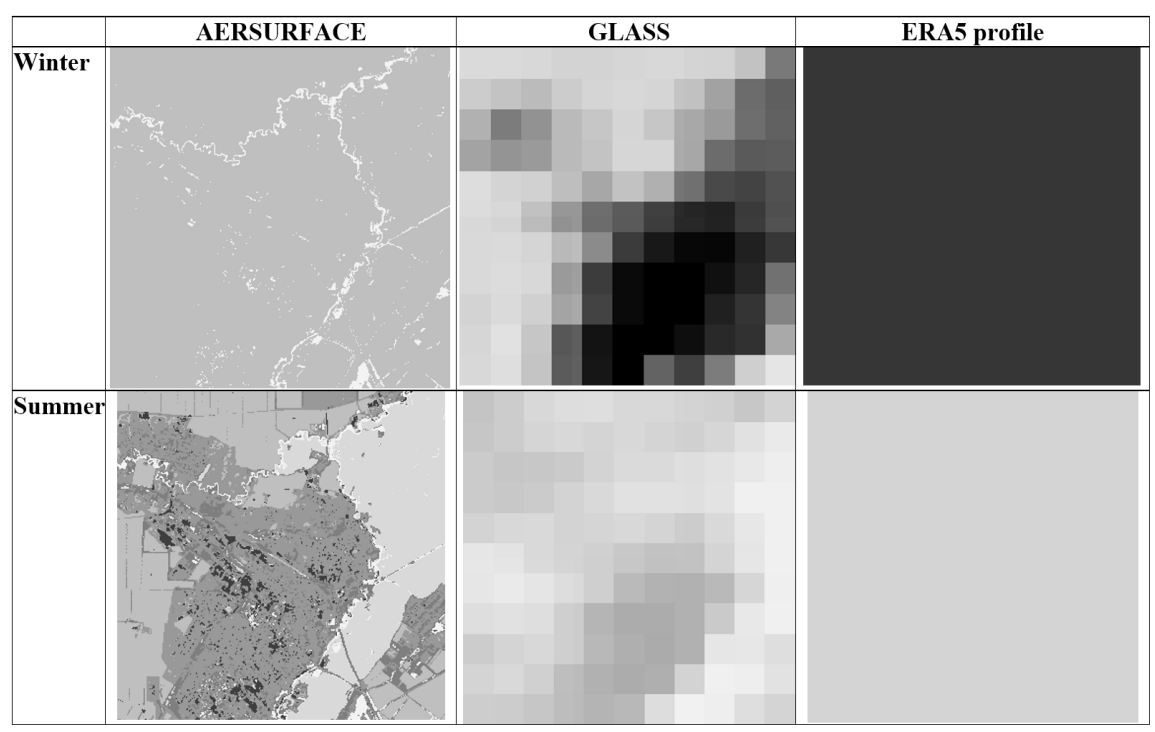

Figure 7. Bowen parameter maps for Plant 2 constructed from AERSURFACE standards and from GLASS and ERA5 data. Black $\geq 2$ values used by AERMOD. 


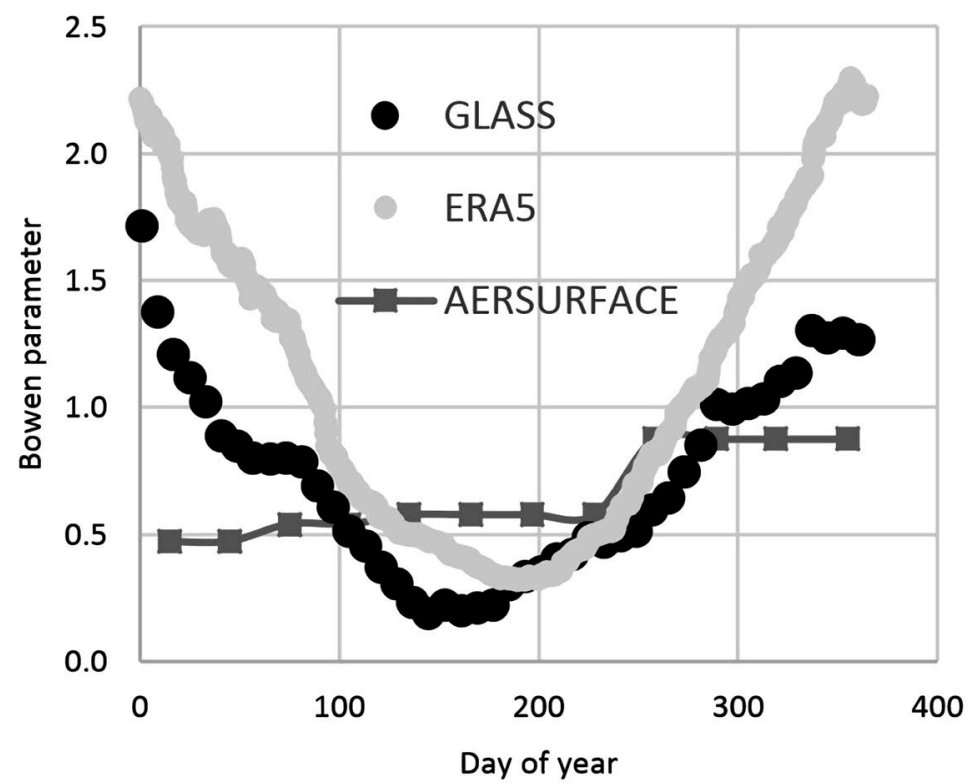

Figure 8. Comparison of seasonal dynamics of Bowen parameter in AERSURFACE and as constructed from GLASS or ERA5. For Plant 2.

Table 6. Absolute differences between maximal hourly concentrations of critical pollutants calculated with AERMOD standards (STD) and with GLASS or ERA5 data for Bowen parameter (NonSTD).

\begin{tabular}{|c|c|c|c|c|c|}
\hline Plant & $\begin{array}{l}\text { RFCac } \\
\mathrm{mg} / \mathrm{m}^{3}\end{array}$ & $\begin{array}{c}\mid \text { (STD-NonSTD }) \mid \\
\text { /RFCac } \\
\text { DiffFirst }\end{array}$ & $\begin{array}{c}\mid \text { (STD-NonSTD }) \mid \\
\text { /STD } \\
\text { DiffFirst }\end{array}$ & $\begin{array}{c}\mid(\text { STD-NonSTD }) \mid \\
\text { /RFCac } \\
\text { Day95\% }\end{array}$ & $\begin{array}{c}\mid \text { (STD-NonSTD }) \\
\text { /STD } \\
\text { Day95\% }\end{array}$ \\
\hline \multicolumn{6}{|c|}{ Average of regions outside exclusion zone } \\
\hline 1 & 0.3 & 0.034 & 0.058 & 0.14 & 0.45 \\
\hline 2 GLASS & 0.2 & 0.1 & 0.03 & 0.076 & 0.44 \\
\hline 2 ERA5 & 0.2 & 0.089 & 0.045 & 0.049 & 0.29 \\
\hline \multicolumn{6}{|c|}{ Critical region } \\
\hline 1 & 0.3 & 0.112 & 0.093 & 0.175 & 0.40 \\
\hline 2 GLASS & 0.2 & 1 & 0.07 & 0.48 & 0.31 \\
\hline 2 ERA 5 & 0.2 & 0.95 & 0.139 & 0.36 & 0.23 \\
\hline
\end{tabular}

in using this data for enhancement and/or replacement of standard values of surface parameters, which are used by AERMOD by default but may be irrelevant for a specific area. A priori, we assume that using remote sensing/reanalysis data for a concrete territory is more accurate than using global AERMOD standards. This is a feasibility study in view of practical/regulatory application, e.g., in establishing the exclusion zones. Therefore, we focus on data that can be used with little user effort. The first choice is the readily available remote sensing reanalysis data but, due to their lower spatial resolution, we also consider using Landsat data.

Three measures of the impact of remote sensing data on model concentrations 
are applied. The ratio of these impact measures to $\mathrm{RFC}_{\text {acute }}$ (understood as admissible limit) is, essentially, a measure of the impact on acute health risk. Usually, we perceive the 0.1 changes in health risk index as considerable. An alternative measure of remote sensing data impact on concentrations/health risks is "relative": calculated with respect to "standard" concentrations, rather than to $\mathrm{RFC}_{\text {acute. }}$. It is especially relevant for comparison between "absolute" and "regulatory" effects since it alleviates the influence of cutting the maxima to $95 \%$ in the latter criterion.

It is well known that of three surface parameters used by AERMOD (albedo, roughness and Bowen ratio), roughness has by far the largest impact on model concentrations. The conclusion had been made mostly from studies of isolated sources. This study supports it for real multi-source industrial complexes, but with qualifications (see below).

Normally, one would consider a combined usage of all three parameters derived from remote sensing/reanalysis data. A measure of such a combined impact is provided by comparing the land use classifications from standard global land use maps (GLC10, GLC30, and MOD12Q1, of which only the first is listed in this paper) to Landsat data classified with local training sites. Changing classes changes all three surface parameters. The effect is, probably, mostly due to roughness; nevertheless, a synergetic effect of parameter changes is also possible. The next step to research this synergy would be to combine together the remote sensing-based estimates of three surface parameters, which in this paper are studied separately.

Seasonal dynamics is an important characteristic of AERMOD parameters reconstructed from remote sensing data. It can serve as a control for applicability of AERMOD standards to specific territories. For albedo, GLASS and Landsat data show more or less the same spatial pattern and seasonal dynamics as AERMOD standards but the values are quite different, especially in winter. For Bowen parameter, the seasonal dynamics constructed from very different data (ERA5 profiles and GLASS surface thermal fluxes) is similar in form (although different in values), which supports its reality. It is radically different from AERMOD standard seasonal dynamics. For roughness, values for built-up territories and forests are constructed from ALOS DEM and have no seasonal dynamics (it is imposed on them according to AERMOD standards). Values for other vegetation types are calculated from NDVI and are more or less compatible with AERMOD standards in summer and autumn but not in winter and spring.

Various measures of impact of remote sensing data on model concentrations and health risk presented in Table 2, Table 3, Table 5, and Table 6 are summarized in Table 7. Strong impact is that $>1$ (in $\mathrm{RFC}_{\mathrm{ac}}$ or relative units), considerable impact is between $0.4-0.5$ and 1 , small between 0.1 and $0.4-0.5$, negligible < 0.1 for all plants.

As usual for real plants, no systematic onsite monitoring of pollutant concentrations is available, therefore we cannot prove that adding the remote sensing 
Table 7. Summary of various measures of remote sensing data impact. Codes: ! strong, + considerable, $\sim$ small, - negligible impact. Aggregated over all plants considered.

\begin{tabular}{|c|c|c|c|c|c|c|c|c|c|}
\hline \multirow[b]{2}{*}{ Measure } & \multirow[b]{2}{*}{ Criterion } & \multicolumn{4}{|c|}{ Full study area for each plant } & \multicolumn{4}{|c|}{ Critical region for each plant } \\
\hline & & Classification & Roughness & Albedo & Bowen & Classification & Roughness & Albedo & Bowen \\
\hline \multirow{3}{*}{$\begin{array}{l}\text { Health risk } \\
\left(/ \mathrm{RFC}_{\mathrm{ac}}\right)\end{array}$} & Absolute & $!$ & $\sim$ & - & - & $!$ & $\sim$ & $\sim$ & - \\
\hline & Regulatory & - & - & - & $\sim$ & $\sim$ & $\sim$ & $\sim$ & + \\
\hline & Instant & $!$ & + & + & $\sim$ & $!$ & $!$ & $!$ & + \\
\hline \multirow{3}{*}{$\begin{array}{l}\text { Relative } \\
\text { (/STD) }\end{array}$} & Absolute & + & $\sim$ & - & - & + & $\sim$ & $\sim$ & - \\
\hline & Regulatory & + & + & $\sim$ & + & + & + & $\sim$ & + \\
\hline & Instant & + & + & + & - & + & + & + & $\sim$ \\
\hline
\end{tabular}

data does actually improve the model estimates of concentrations. However, this seems a reasonable assumption.

\section{Conclusion}

Using remote sensing data is justified, with "absolute" criterion, in critical regions for albedo and everywhere, for roughness and classification. With "regulatory" criterion, which somewhat suppresses the dominant role of nighttime, stable atmosphere concentrations, the judgement depends on the measure used. Measured against $\mathrm{RFC}_{\mathrm{ac}}$, using remote sensing data is justified for Bowen parameter everywhere and for other parameters in critical regions only. However, measured "relatively", justification is for all parameters everywhere. With "instant" criterion, the use of remote sensing data is justified everywhere except for the Bowen parameter, for which it is justified in critical regions only.

We consider this study as a contribution to future assimilation of remote sensing/climatic model data into pollution dispersion models, especially important for developing countries. Hopefully, this study will help to choose where to concentrate the effort.

\section{Acknowledgements}

The author acknowledges the contribution of Maria Stalnaya and Dmitrii Balter to data processing and of Boris Balter, to discussion of methodology and results.

\section{Conflicts of Interest}

No potential conflict of interest is reported by the author.

\section{References}

(2008). Aersurface User's Guide. Research Triangle Park, NC: US Environmental Protection Agency.

Baldinelli, G., Bonafoni, S., \& Rotili, A. (2017). Albedo Retrieval from Multispectral Landsat 8 Observation in Urban Environment: Algorithm Validation by in Situ Measurements. IEEE Journal of Selected Topics in Applied Earth Observations and Remote 
Sensing, 10, 4504-4511. https://doi.org/10.1109/JSTARS.2017.2721549

Balter, B., Balter, D., Egorov, V., Stalnaya, M., \& Faminskaya, M. (2018). Landsat Land Use Classification for Assessing Health Risk from Industrial Air Pollution. Izvestiya, Atmospheric and Oceanic Physics/ Issledovanie Zemli iz kosmosa, 9, 1334-1340. https://doi.org/10.1134/S0001433818090062

Balter, B., \& Faminskaya, M. (2017). Irregularly Emitting Air Pollution Sources: Acute Health Risk Assessment Using AERMOD and the Monte Carlo Approach to Emission Rate. Air Quality, Atmosphere \& Health, 10, 401-409. https://doi.org/10.1007/s11869-016-0428-x

Bastiaanssen, W., \& Roebeling, R. A. (1993). Analysis of Land Surface Exchange Processes in Two Agricultural Regions in Spain Using Thematic Mapper Simulator Data. Exchange Processes at the Land Surface for a Range of Space and Time Scales. In Proceedings of the Yokohama Symposium (pp. 407-416). Yokohama: IAHS Publ. No. 212.

Bastiaanssen, W., Menenti, M., Feddes, R. A., \& Holtslag, A. A. M. (1998a). A Remote Sensing Surface Energy Balance Algorithm for Land (SEBAL) 1. Formulation. Journal of Hydrology, 212-213, 198-212. https://doi.org/10.1016/S0022-1694(98)00253-4

Bastiaanssen, W., Pelgrum, H., Wang, J., Ma, Y., Moreno, J., Roerink, G. J., \& van der Wal, T. (1998b). A Remote Sensing Surface Energy Balance Algorithm for Land (SEBAL) 2. Validation. Journal of Hydrology, 212-213, 212-229. https://doi.org/10.1016/S0022-1694(98)00254-6

Bo, X., Wang, G., Tian, J., Yang, J., Gao, X., Huang, Y., \& Li, S. (2015). Standard Systems of Surface Parameters in AERMOD. China Environmental Science, 35, 2570-2575. (In Chinese)

Cho, J., Miyazaki, S., Yeh, P. J. F., Kim, W., Kanae, S., \& Oki, T. (2012). Testing the Hypothesis on the Relationship between Aerodynamic Roughness Length and Albedo Using Vegetation Structure Parameters. International Journal of Biometeorology, 56, 411-418. https://doi.org/10.1007/s00484-011-0445-2

Garcia-Mora, T., Mas, J. F., \& Hinkley, E. A. (2012). Land Cover Mapping Applications with MODIS: A Literature Review. International Journal of Digital Earth, 5, 63-87. https://doi.org/10.1080/17538947.2011.565080

Gowda, P, Chávez, J. L., Howell, T. A., Marek, T. H., \& New, L. L. (2008). Surface Energy Balance Based Evapotranspiration Mapping in the Texas High Plains. Sensors, 8, 5186-5201. https://doi.org/10.3390/s8085186

Grosch, T., \& Lee, R. F. (1999). Sensitivity of the AERMOD Air Quality Model to the Selection of Land Use Parameters. Transactions on Ecology and the Environment, 29, 803-812.

Gupta, R., Prasad, T. S., \& Vijayan, D. (2002). Estimation of Roughness Length and Sensible Heat Flux from WiFS and NOAA AVHRR Data. Advances in Space Research, 29, 33-38. https://doi.org/10.1016/S0273-1177(01)00624-X

He, T., Wang, D., \& Qu, Y. (2018). Land Surface Albedo. In S. Liang (Ed.), Comprehensive Remote Sensing. Volume 5: Earth's Energy Budget (pp. 140-162). Amsterdam: Elsevier. https://doi.org/10.1016/B978-0-12-409548-9.10370-7

Isakov, V., Venkatram, A., Touma, J. S., Koracin, D., \& Otte, T. L. (2007). Evaluating the Use of Outputs from Comprehensive Meteorological Models in Air Quality Modeling Applications. Atmospheric Environment, 41, 1689-1705.

https://doi.org/10.1016/j.atmosenv.2006.10.043

Karvounis, G., Deligiorgi, D., \& Philippopoulos, R. (2007). On the Sensitivity of AERMOD to Surface Parameters under Various Anemological Conditions. In Proceedings of the 
11th International Conference on Harmonisation within Atmospheric Dispersion Modelling for Regulatory Purposes (pp. 43-47). Cambridge: Cambridge Environmental Research Consultants Ltd.

Kent, C., Grimmond, S., Gatey, D., \& Hirano, K. (2019). Urban Morphology Parameters from Global Digital Elevation Models: Implications for Aerodynamic Roughness and for Wind-Speed Estimation. Remote Sensing of Environment, 221, 316-339.

https://doi.org/10.1016/j.rse.2018.09.024

Kesarkar, A., Dalvi, M., Kaginalkar, A., \& Ojhab, A. (2007). Coupling of the Weather Research and Forecasting Model with AERMOD for Pollutant Dispersion Modeling. A Case Study for PM10 Dispersion over Pune, India. Journal of Atmospheric Environment, 41, 1976-1988. https://doi.org/10.1016/j.atmosenv.2006.10.042

Kumar, A., Patil, R. S., Dikshit, A. K., \& Kumar, R. (2017). Application of WRF Model for Air Quality Modelling and AERMOD-A Survey. Aerosol and Air Quality Research, 17, 1925-1937. https://doi.org/10.4209/aaqr.2016.06.0265

Liang, S., Wang, D., He, T., \& Yu, Y. (2019). Remote Sensing of Earth's Energy Budget: Synthesis and Review. International Journal of Digital Earth, 12, 737-780. https://doi.org/10.1080/17538947.2019.1597189

Lindberg, F., Grimmond, C. S. B., \& Gabey, A. (2018). Urban Multi-Scale Environmental Predictor (UMEP): An Integrated Tool for City-Based Climate Services. Environmental Modelling \& Software, 99, 70-87. https://doi.org/10.1016/j.envsoft.2017.09.020

Malek, E. (1993). Comparison of the Bowen Ratio-Energy Balance and Stability-Corrected Aerodynamic Methods for Measurement of Evapotranspiration. Theoretical and Applied Climatology, 48, 167-178. https://doi.org/10.1007/BF00864923

Pape, M., \& Vohland, M. (2010). A Comparison of Total Shortwave Surface Albedo Retrievals from MODIS and TM Data. In ISPRS TC VII Symposium (Vol. 38, pp. 447-451). Vienna: IAPRS.

Pongprueksa, P., \& Chatchupong, T. (2016). High Resolution Land Cover Data for Thailand's Air Quality Impact Assessment. In 5th International Conference on Environmental Engineering, Science and Management (pp. 1-6). Bangkok.

Simpson, M., Jasinski, M. F., Borak, J., Blonski, S., Spruce, J., Walker, H., \& Delle Monache, L. (2012). Integrating NASA Earth Science Capabilities into the Interagency Modeling and Atmospheric Assessment Center for Improvements in Atmospheric Transport and Dispersion Modeling. Lawrence Livermore National Laboratory, LLNL-TR-596732. https://doi.org/10.2172/1055855

Tadono, T., Nagai, H., Ishida, H., Oda, F., Naito, S., Minakawa, K., \& Iwamoto, H. (2016). Generation of the $30 \mathrm{~m}$-Mesh Global Digital Surface Model by ALOS PRISM. In The International Archives of the Photogrammetry, Remote Sensing and Spatial Information Sciences XLI-B4. XXIII ISPRS Congress (pp. 157-162). Prague.

https://doi.org/10.5194/isprsarchives-XLI-B4-157-2016

Zhao, X., Liang, S., \& Liu, S. (2013). The Global Land Surface Satellite (GLASS) Remote Sensing Data Processing System and Products. Remote Sensing, 5, 2436-2450.

https://doi.org/10.3390/rs5052436 